\title{
Functional abdominal pain: further evidence that whole gut is affected
}

\author{
KIERAN J MORIARTY, ANTHONY M DAWSON
}

\begin{abstract}
The distribution and referral of abdominal pain in 21 patients with functional abdominal pain were investigated by performing balloon distension of the ileum, proximal jejunum, second part of the duodenum, and distal oesophagus. Pain was perceived not just in classically described sites but throughout the abdomen and was referred to several unusual extra-abdominal sites. The presenting pain was reproduced by this technique in 14 patients, in three of whom it was also reproduced by colonoscopic distension.

This study emphasises the protean presentation of functional abdominal pain and demonstrates the existence of potentially tender "trigger" areas for the production of abdominal pain in the proximal as well as the distal gut.
\end{abstract}

\section{Introduction}

Functional abdominal pain for which no organic cause is found is common. The classical textbook teaching is that visceral pain is felt predominantly in the midline and that the level at which it is perceived corresponds to the dermatomes from which the diseased organ receives its innervation. ${ }^{1-5}$ Such teaching is based on information derived from balloon distension of the gut in several classical studies. ${ }^{6-9}$ Pain arising from the oesophagus was perceived in the retrosternal region, from the duodenum in the epigastrium, from the jejunum and ileum in the periumbilical region, and from the colon in the lower abdomen, all in the midline. In these studies there was no mention of referral of pain to extra-abdominal sites.

A better defined subgroup of patients with functional abdominal pain is those with the irritable bowel syndrome, in which there is disturbed bowel action. ${ }^{1011}$ This syndrome does not, however, include all patients with functional abdominal pain, who nevertheless have a similar pain and natural history. Abdominal pain occurring in the irritable bowel syndrome is usually assumed to originate from the colon, but in 45 patients Waller and Misiewicz ${ }^{10}$ observed that pain was not in the midline and occurred anywhere in the abdomen, while 12 patients experienced pain in more than one site. This might partly be explained by the observations of Swarbrick et al, ${ }^{12}$ who found that pain caused by colonic distension in patients with functional abdominal pain often had bizarre localisation and referral patterns and differed from the findings in normal patients. Pain was not, however, reproduced by colonic distension in all subjects. We therefore wondered whether other areas of the alimentary tract might act as a trigger point for the production of pain.

The aims of the present study were twofold: firstly, to study the distribution and referral of pain caused by proximal gut distension in patients with functional abdominal pain and, secondly, to see whether such distension would reproduce the spontaneous pain.

Department of Gastroenterology, St Bartholomew's Hospital, London EC1A 7BE

KIERAN J MORIARTY, MB, MRCP, clinical research fellow ANTHONY M DAWSON, MD, FRCP, consultant physician

\section{Patients and methods}

We studied 21 patients (six men, 15 women) aged 19-69 years. All suffered from chronic functional abdominal pain, and in six there was more than one site. The diagnosis was essentially one of exclusion, all patients having been extensively investigated to rule out organic disease. Nine patients had normal bowel movements, six had diarrhoea, and six were constipated. ${ }^{13}$ Eight had undergone 15 previous operations specifically to investigate their pain (five laparotomy, three appendicectomy, one combined laparotomy and appendicectomy, two cholecystectomy, one hysterectomy, one hiatus hernia repair, one vagotomy and pyloroplasty, and one coccydectomy). Pain had persisted or recurred soon after operation in all cases. Between them they had consulted 57 hospital specialists.

The patients were admitted to hospital and swallowed a tube (Portex) incorporating a balloon (London Rubber Co) and mercury bag filled with $3 \mathrm{ml}$ mercury. This was passed under fluoroscopic screening to the ileum, and during withdrawal the balloon was inflated in the ileum, proximal jejunum, second part of the duodenum, and distal oesophagus. The balloon was inflated until the patient first perceived pain to a maximum volume of $100 \mathrm{ml}$. Thirteen patients also underwent colonoscopy with inflation of an attached balloon. ${ }^{12}$

\section{Results}

Sites of induced pain-Figure 1 shows the distribution of pain induced by balloon distension of the ileum, proximal jejunum, second part of the duodenum, and distal oesophagus. When pain was felt in
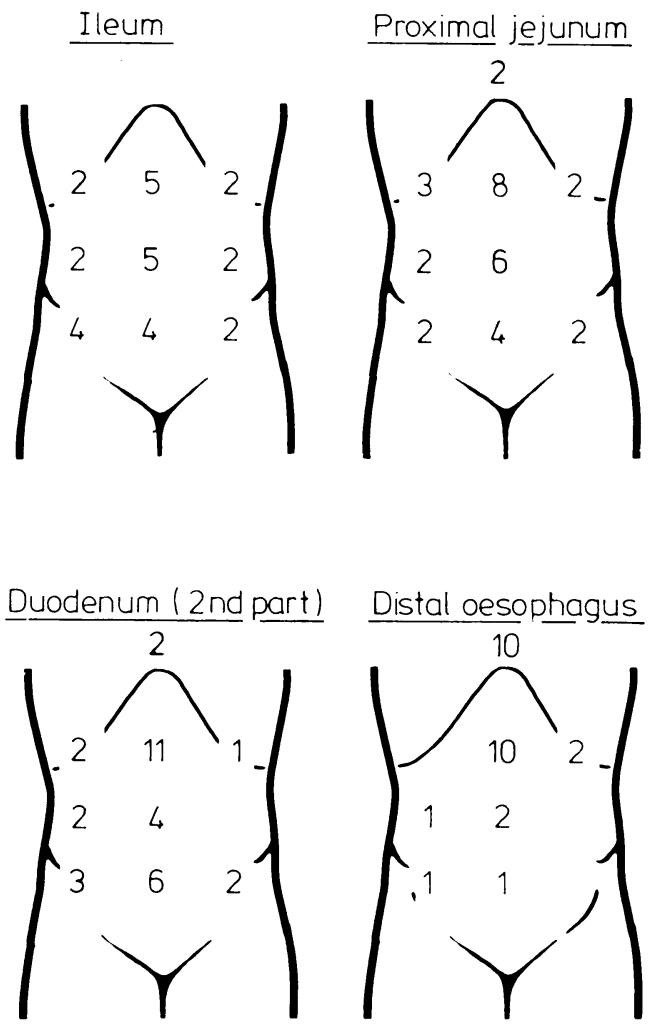

FIG 1-Distribution of pain induced by inflation of balloon in ileum, proximal jejunum, second part of duodenum, and distal oesophagus in 21 patients. Numbers in each sector represent number of patients perceiving pain at that site during balloon inflation. Sites to which pain was referred are not included. 
more than one site all areas were scored. In all three parts of the small intestine pain was experienced not only in the "classical" sites but elsewhere in the abdomen and in two patients retrosternally. Balloon distension of the distal oesophagus produced pain not only in the retrosternal region, as expected, ${ }^{9}$ but also in the epigastrium and various other abdominal sites.

Reproduction of spontaneous pain-The spontaneous pain of which the patient complained was reproduced by distension of either the oesophagus or the small intestine in 14 of the 21 patients in both central and lateral sites (fig $2(a)$ ). Eight of the 14 patients in whom pain was reproduced also underwent balloon colonoscopy; in three of these colonic distension also reproduced their pain, both in site and in character (fig $2(b)$ ). Therefore there may be more than one trigger area for the production of pain, and trigger areas may exist in both the upper and lower gut. Figure 3 shows the sites of pain in the six patients in whom we were able to reproduce the spontaneous pain by distension not only of the small intestine but also of the distal oesophagus. Thus

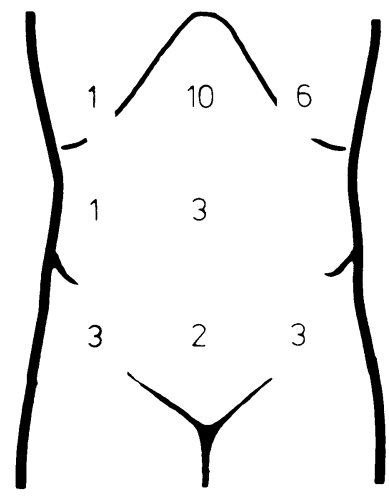

(a)

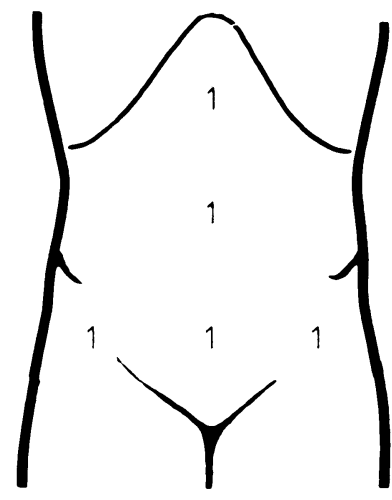

(b)
FIG $2-(a)$ Sites of pain reproduced by proximal gut distension in 14 patients. (b) Sites of pain reproduced by distension of both colon and proximal gut in three patients.

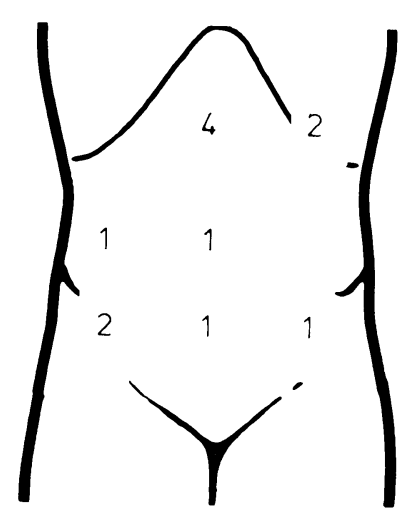

FIG 3-Sites of abdominal pain that was reproduced by distension of both small intestine and distal oesophagus in six patients.

these patients had at least two trigger areas that produced their pain, one above and one below the diaphragm. Oesophageal distension reproduced the presenting abdominal pain in several unexpected sites.

Failure to reproduce spontaneous pain by proximal gut distensionProximal gut distension failed to reproduce the presenting pain in seven patients in a total of 10 sites (three in the right hypochondrium, one in the epigastrium, two in the left hypochondrium, three in the right iliac fossa, and one in the left iliac fossa). Six of these seven patients also underwent balloon colonoscopy, which reproduced pain in three (two in the right iliac fossa and one in the left hypochondrium). In all, we failed to reproduce spontaneous pain in four of the 21 patients studied. Although the numbers were small, right hypochondrial pain seemed particularly difficult to reproduce, and we failed to do so in three of the four patients studied. Colonoscopic distension, however, reproduced right hypochondrial pain in four of seven patients in the study of Swarbrick et al. ${ }^{12}$

Extra-abdominal referral of pain arising from the small intestineDistension of the small intestine caused referral of pain to several sites-namely, the back (straight through, one case; both sides, two; right side, two; left side, two), the left lower ribs (one case), both breasts (one), the left breast (one), and retrosternally (two). In all, extra-abdominal referral of pain occurred in 10 patients, in six of whom it was the characteristic referral of pain that the patient experienced normally.

\section{Discussion}

Hurst $^{14}$ was the first to show that pain was produced by balloon insufflation of the gut. Before that it had been thought that the viscera were insensitive and that any pain arising from them was due to irritation of the adjacent parietal peritoneum. ${ }^{15}$ Some workers $^{1416}$ believed that the sensation of pain was caused by tension in the muscle wall of a diseased viscus and others ${ }^{17-19}$ that it was transmitted by the attached sensory nerves. Alvarez, ${ }^{20}$ however, believed that it was due to neither of these, attributing it instead to stretching of the attached mesentery. In a series of carefully designed studies Ray and Neill' ${ }^{8}$ showed that pain sensitivity existed in the proximal mesentery and at the mesenteric-visceral junction but not in the gut wall itself. These studies, however, have been largely forgotten, and abdominal tenderness is still widely believed to indicate inflammation of the parietal peritoneum, an assumption known to be misguided by any clinician who has palpated a tender sigmoid colon in a patient with the irritable bowel syndrome and one that doubtless results occasionally in inappropriate surgery.

The results of this study show, firstly, that balloon distension of the small intestine and distal oesophagus can both induce and reproduce spontaneous pain throughout the abdomen in patients with functional abdominal pain and, secondly, that the site of referral may be anywhere in the abdomen. This contrasts with results of previous studies in normal and hypertensive patients ${ }^{6-9}$ but is analogous to earlier observations on colonic distension in patients with the splenic flexure syndrome ${ }^{21}$ and by Swarbrick et $a l^{12}$ in patients with spontaneous abdominal pain.

By performing balloon colonoscopy we were able to reproduce in three patients their characteristic presenting pain, which was not reproduced by proximal gut distension. In all, colonic distension reproduced the presenting pain in six of the 14 patients in whom it was performed. This compares with the study of Swarbrick et al, ${ }^{12}$ in which the presenting pain was reproduced in 29 out of 48 patients. Ours, however, was a selected group of patients whose pain was not classically colonic, ${ }^{22}$ and in some proximal gut distension was performed specifically because their pain had not been reproduced by colonic distension.

Distension of the proximal as well as the distal gut reproduced spontaneous functional abdominal pain both in site and in character in several patients, which shows that trigger areas for the production of such abdominal pain may exist in the oesophagus and small intestine as well as the colon in the same patient.

While our observations emphasise the sensitivity of the small intestine, other workers have investigated small-intestinal motility in patients with functional abdominal pain. Both ileal and jejunal hypermotility have been found coincident with abdominal pain in these patients. ${ }^{23-27}$ These changes may occur in isolation or simultaneously with increased colonic motility. ${ }^{23-24}$ Abnormal sensitivity as well as disturbed motility are probably important mechanisms in causing functional abdominal pain, not only in the colon but also elsewhere in the gastrointestinal tract. Regarding the contribution of the foregut to functional abdominal pain, Sekar et al suggested that duodenogastric reflux is important in some patients in the pathogenesis of non-ulcer dyspepsia, ${ }^{28}$ while in other patients increased sensitivity of the oesophagus has been shown. ${ }^{29}$

In those patients in whom we were unable to reproduce their presenting pain it might be speculated that tenderness 
of the alimentary tract was intermittent or more localised than we explored, similar to the localised tender segments in the oesophagus described by Edwards. ${ }^{29}$ Alternatively, pain may arise in other areas such as the pancreas or biliary tract or in some cases from a non-alimentary source.

Referral of pain to extra-abdominal sites has now been shown from the small as well as the large bowel. A wider appreciation of the protean presentation of functional abdominal pain and the existence of potential tender areas throughout the whole gut should expedite the recognition of non-organic abdominal pain and prevent unnecessary investigations and even exploratory laparotomy.

KJM is in receipt of a Medical Research Council training fellowship.

\section{References}

${ }^{1}$ Isselbacher $\mathrm{KJ}$. Indigestion. In: Isselbacher $\mathrm{KJ}$, Adams RD, Braunwald EB, Petersdorf RG, Wilson JD, eds. Harrison's principles of internal medicine. 9th ed. Maidenhead: McGraw-Hill, 1980:195.

${ }^{2}$ Hawkins CF. The alimentary system. In: Mann WN, ed. Conybeare's textbook of medicine. 16th ed. Edinburgh: Churchill Livingstone, 1977:285.

${ }^{3}$ Way LW. Abdominal pain and the acute abdomen. In: Sleisenger $M H$, Fordtran JS, eds. Gastrointestinal disease. 2nd ed. Eastbourne: W B Saunders, 1978:398-404

${ }^{4}$ Rains AJH, Ritchie HD, eds. The intestines. In: Bailey and Love's short practice of surgery. 18th ed. London: Lewis, 1981:990.

${ }^{5}$ Schwartz SI, Shires GT, Spencer FC, Storer EH, eds. Manifestations of gastrointestinal disease. In: Principles of surgery. 3rd ed. Maidenhead: McGraw-Hill, 1979:1043.

6 Jones CM. Digestive tract pain. New York: Macmillan, 1938:8.

7 Bentley FH, Smithwick RH. Visceral pain produced by balloon distension of the jejunum. Lancet 1940;ii:389.

8 Ray BS, Neill CL. Abdominal visceral sensation in man. Ann Surg 1947; $126: 709-24$.

- Chapman WP, Jones CN. Variations in cutaneous and visceral pain sensitivity in normal subjects. $\mathcal{F}$ Clin Invest $1944 ; 23: 81-91$.

10 Waller SL, Misiewicz JJ. Prognosis in the irritable-bowel syndrome. Lancet 1969 ;ii :753-6.
11 Manning AP, Thompson WG, Heaton $\mathrm{KW}$, Morris AF. Towards positive diagnosis of the irritable bowel. Br Med F 1978;ii:653-4.

12 Swarbrick ET, Hegarty JE, Bat L, Williams CB, Dawson AM. Site of pain from the irritable bowel. Lancet 1980;ii:443-6.

${ }^{13}$ Connell AM, Hilton C, Irvine G, Lennard-Jones JE, Misiewicz JJ. Variation of bowel habit in two population samples. Br Med $\mathcal{f} 1965$; ii:1095-9.

14 Hurst AF. On the sensibility of the alimentary canal in health and disease. Lancet $1911 ; \mathrm{i}: 1051,1119,1187$.

15 Lennander KG. Uber die Sensibilität der Bauchhöhle und über lokale und allgemeine Anästhesie bei bruchund Bauchoperationen. Zentralbl Chir $1901 ; 28: 209$.

${ }^{16}$ Ryle JA. Visceral pain and referred pain. Lancet 1926;i:895.

${ }_{17}$ Payne WW, Poulton EP. Visceral pain in the upper alimentary tract. $Q \mathcal{F}$ Med 1923;17:53.

${ }^{18}$ Payne WW, Poulton EP. Experiments on visceral sensation. 7 Physio $1927 ; 63: 217$.

19 Morley J. Visceral pain. Br Med f 1937;ii:1270.

${ }^{20}$ Alvarez WC. Abdominal pain: the sensitive regions of the abdomen and ways in which they may be stimulated to produce pain. $\mathcal{f} A M A 1934$ 102: 1351 .

${ }^{21}$ Dworken HJ, Biel FJ, Machella TE. Supradiaphragmatic reference of pain from the colon. Gastroenterology 1952;22:222-9.

22 Thompson WG, Heaton KW. Functional bowel disorders in apparently healthy people. Gastroenterology 1980;79:283-8.

${ }^{23}$ Holdstock DJ, Misiewicz JJ, Waller SL. Observations on the mechanism of abdominal pain. Gut 1969;10:19-31.

${ }^{24}$ Connell AM, Jones FA, Rowlands EN. Motility of the pelvic colon. IV. Abdominal pain associated with colonic hypermotility after meals. Gu $1965 ; 6: 105-12$.

${ }^{25}$ Horowitz L, Farrar JT. Intraluminal small intestinal pressures in normal patients and in patients with functional gastrointestinal disorders. Gastroenterology 1962;42:455-64.

${ }^{26}$ Kalser MH, Zion DE, Bockus HL. Functional diarrhoea : an analysis of the clinical and roentgen manifestations. Gastroenterology 1956;31:629-46.

27 Thompson DG, Laidlow JM, Wingate DL. Abnormal small-bowe motility demonstrated by radiotelemetry in a patient with irritable colon. Lancet 1979;ii:1321-3.

${ }^{28}$ Sekar ASC, Thompson WG, Turner LJ, Barr R. Duodeno-gastric reflux and gastritis in non-ulcer dyspepsia. Clinical Research 1977;24:667A

29 Edwards DAW. History and symptoms of oesophageal disease. Diseases of the oesophagus. In: Vantrappen G, Hellemans J, eds. Handbuch der inneren Medizin. Berlin, Heidelberg, New York: Springer-Verlag, 1974:112.

(Accepted 23 April 1982)

\section{SHORT REPORTS}

\section{"Scalded mouth" caused by angiotensin-converting-enzyme inhibitors}

Captopril, an angiotensin-converting-enzyme inhibitor, is used to treat resistant hypertension. ${ }^{1}$ Side effects include rash, proteinuria, leukopenia, ageusia, angio-oedema, and aphthous and tongue ulcers; its sulphydryl moiety may be an aetiological factor. ${ }^{1}$ Enalapril, a new converting-enzyme inhibitor, does not contain a sulphydryl group. ${ }^{2}$ We describe three patients who reported a scalded sensation of the oral mucosa during treatment with captopril or enalapril.

\section{Case reports}

Case 1-A 53-year-old hypertensive woman receiving hydrochlorothiazide $50 \mathrm{mg}$ daily was prescribed captopril $12.5 \mathrm{mg}$ thrice daily in addition; she took no other medication. After two weeks the dosage of captopril was increased to $25 \mathrm{mg}$ thrice daily. Six days later she complained of a burning sensation on the upper surface of her tongue, comparable to having been "scalded by a hot liquid," though she had no recollection of such an occurrence. Examination of her tongue and mouth was unremarkable. She reported no alteration in taste. With her consent the regimen was continued, the symptom persisted for five days and then dissipated despite two additional weeks of captopril treatment, without subsequent recurrence.

Case 2-During a research study a 54-year-old man with essential hypertension received enalapril $20 \mathrm{mg}$ twice daily. Seven days later he said that his tongue and mouth felt as though they had been "scalded by coffee or pizza," though he could not recall such an occurrence. Examination of the mouth showed only periodontal disease and questionable hyperaemia; neurological evaluation including taste perception was normal. He took no other medications. He continued treatment with enalapril for four additional days without resolution. The symptom abated, however, when enalapril was stopped, and he was treated with hydrochlorothiazide $50 \mathrm{mg} /$ day. Two weeks later enalapril was restarted in a dose of $20 \mathrm{mg}$ daily, the diuretic being continued. On the twelfth day of treatment he again complained of the "scaldedmouth" sensation, which was similar to but milder than the first episode. This continued for the next two days but abated when enalapril was stopped at the end of the trial. Similar symptomatology did not recur.

Case 3-A 64-year-old hypertensive woman taking propranolol $160 \mathrm{mg}$ and hydrochlorothiazide $50 \mathrm{mg}$ daily was prescribed captopril $25 \mathrm{mg}$ thrice daily in addition. Other medications included nitroglycerine and isosorbide dinitrate. After two weeks the captopril dosage was increased to $50 \mathrm{mg}$ thrice daily. Nine weeks later she complained of a burning sensation in her throat, palate, and tongue. Examination of the mouth was unremarkable. After two additional weeks of treatment with captopril the symptoms persisted and mild injection at the margins of the soft palate was noted; there was no alteration in taste. Because of continued discomfort captopril was stopped with a distinct improvement during the next week; slight discomfort, however, localised to the tip of her tongue, persisted.

\section{Comment}

Although disorders of taste as well as aphthous and tongue ulcers have been reported during captopril treatment,$^{3-5}$ the symptom described by our patients has not, to our knowledge, been previously associated with use of either captopril or enalapril. The mechanism of this side effect is unclear. Neither fever nor eosinophilia accompanied the patients' complaints. No concomitant laboratory abnormalities were noted, and all the patients had normal renal function. Since the side effect was noted with both captopril and enalapril the aetiology of this scalded-mouth reaction appears to be independent of the sulphydryl moiety of captopril. The hyperaesthesia of the oral mucosa abated during continued treatment with captopril in case 1 , recurred 